\title{
Conventional surgical techniques and emerging transplantation in complex penile reconstruction
}

\author{
Nima Khavanin, Richard J. Redett \\ Department of Plastic and Reconstructive Surgery, Johns Hopkins University School of Medicine, Baltimore, MD 21287, USA.
}

Correspondence to: Dr. Richard J. Redett, Department of Plastic and Reconstructive Surgery, Johns Hopkins University School of Medicine, 601 N Caroline St, Baltimore, MD 21287, USA. E-mail: rjr@jhmi.edu

\begin{abstract}
How to cite this article: Khavanin N, Redett RJ. Conventional surgical techniques and emerging transplantation in complex penile
\end{abstract} reconstruction. Plast Aesthet Res 2020;7:47. http://dx.doi.org/10.20517/2347-9264.2020.63

Received: 7 Apr 2020 First Decision: 19 Jun 2020 Revised: 20 Jun 2020 Accepted: 30 Jul 2020 Published: 1 Sep 2020

Academic Editor: Marlon E. Buncamper Copy Editor: Cai-Hong Wang Production Editor: Jing Yu

\begin{abstract}
Complex penile reconstruction continues to pose a significant challenge to surgeons and patients alike. The ideal phalloplasty is one that can be reproducibly performed in a single stage, creates a neourethra that allows for voiding while standing, produces a phallus with tactile and erogenous sensation, allows for penetrative sexual intercourse, and offers satisfactory aesthetic results. With recent advances in microsurgery and perforator flap dissection, several techniques and modifications thereof have been described that aim to achieve these reconstructive goals. All of these now conventional techniques, however, fall short in one way or another - often with regards to urinary transport, the ability to achieve an erection, and the need for multiple surgical stages and revision operations. These limitations of conventional reconstruction have led some surgeons to explore new avenues for complex penis reconstruction, giving birth to the novel field of penile transplantation. In this article, we discuss the complexities of male genitourinary reconstruction in the context of conventional methods for reconstruction as well as the burgeoning field of penile transplantation.
\end{abstract}

Keywords: Phalloplasty, total penile reconstruction, free flap, vascularized composite allotransplantation, penis transplantation, reconstructive surgery, urologic reconstruction

\section{INTRODUCTION}

Despite nearly a century's worth of cumulative experience in complex penile reconstruction, the ideal neophallus continues to elude us, presenting a significant challenge to reconstructive surgeons. The first 
attempted total penile reconstruction was reported in 1936 by Russian surgeon Nikolaj Bogoraz ${ }^{[1]}$. His use of a bipedicle abdominal flap with rib cartilage aimed to provide stiffness for potential sexual intercourse, but fell short of attempting urethral reconstruction or taking measures to ensure adequate protective and/ or erogenous sensation. In 1948, Gilles and Harrison ${ }^{[2]}$ expanded upon this technique to introduce the contemporary "tube within a tube" design for creation of the neourethra; however, reconstruction required three or more stages and yielded highly variable results.

Since then, the advent of microsurgical techniques has vastly expanded our toolkit in complex genitourinary reconstruction, enabling substantial improvements in function and aesthetic outcomes. Free tissue transfer using the radial forearm free flap (RFFF), anterolateral thigh flap (ALT), fibular osteocutaneous flap (FOF), and latissimus dorsi myocutaneous flap (LDMF) allow for the transfer of a large amount of tissue in a single surgical procedure with relatively minimal donor site morbidity ${ }^{[3,4]}$. Our improved understanding of nerve regeneration and coaptations has allowed for the preservation of erogenous sensation and the ability to achieve orgasm in most cases ${ }^{[5,6]}$. Most recently, building upon the global experience in hand and face allotransplantation, penile transplantation has emerged as a viable alternative in carefully selected patient populations, promising to even further advance the potential of penile reconstruction ${ }^{[7-11]}$.

Despite these advances, there is no consensus on the ideal reconstructive approach, and, in many cases, complications are both commonplace and potentially serious. In this article, we aim to review the goals of complex penile reconstruction and to discuss the various surgical options within this context. We discuss both "conventional" microsurgical techniques and the emerging field of penile transplantation, including its various technical and ethical considerations ${ }^{[7-11]}$.

\section{EPIDEMIOLOGY}

There are several distinct patient populations who undergo phalloplasty including those who seek oncologic reconstruction, traumatic reconstruction, gender affirming surgery, and correction of congenital abnormalities. Although males with anxiety regarding small penis size may occasionally seek consultation for phalloplasty, surgery is rarely indicated in this patient population, as many benefit from expert psychosexual therapy alone.

Oncologic penectomy, although relatively uncommon, may be increasing in its prevalence with considerable variations in its incidence geographically ${ }^{[3]}$. Squamous cell carcinoma of the penis makes up 0.4\%-0.6\% of all malignancies within Europe and the United States ${ }^{[3]}$. In 2019 alone, the estimated number of new cases of penile cancers in the United States was $2080^{[12]}$. The incidence is increased by as much as $10 \%$ in other parts of the world including South America, Africa, and Asia, with reports that it accounts for as many as $17 \%$ of all malignancies in certain areas of Brazil ${ }^{[13]}$. The most common age of presentation is between 50 and 70 years ${ }^{[14]}$.

Trauma is a well-established etiology for genitourinary injury; nonetheless, the incidence of penile trauma has not been well described. Recent conflicts in Iraq and Afghanistan have brought to light the potentially devastating consequences of male genitourinary trauma. Although these injuries are not new, with historical rates of injury between $0.5 \%$ and $8 \%$ in World War II and Vietnam, the increased use of improvised explosive devises and improvements in body armor that result in more soldiers surviving previously fatal injuries increased the rate to $14 \%$ of all servicemen in $2011^{[15,16]}$. It is important to note that a large percentage of service members who sustain penile trauma present with concomitant multiextremity trauma and/or amputation that minimizes the availability of donor tissue for reconstruction. Of the 1367 male servicemen who sustained genitourinary trauma in Operation Iraqi Freedom and Operation Enduring freedom, $28.7 \%$ sustained at least one extremity amputation as well ${ }^{[17]}$. 
The true incidence of transgender or gender nonconforming patients has been difficult to identify, and the proportion of those patients who are interested in pursuing phalloplasty is even less clear. Recent estimates suggest that $0.6 \%$ of the United States' population identifies as transgender or gender nonconforming ${ }^{[18]}$. The rate of phalloplasty within this population is further confounded by challenges related to health insurance availability and coverage of hormonal and surgical therapy. Nonetheless, gender affirming phalloplasty remains a major area of unmet demand, with many patients experiencing wait times of several years or more ${ }^{[3]}$.

Among children the most common indications for phalloplasty include ambiguous genitalia, micropenis/ severe penile inadequacy, aphallia, and phallic inadequacy associated with epispadias/bladder exstrophy ${ }^{[19]}$. Bladder and cloacal exstrophy have reported incidences of 1:10,000 to 1:50,000 and 1:200,000 to 1:400,000 live births, respectively ${ }^{[20]}$. Male children with bladder or cloacal exstrophy may have ambiguous genitalia, and, historically, some of these patients have been gender-converted to female during infancy and later decide to pursue phalloplasty as an adolescent or adult.

\section{ANATOMY}

The intricate anatomy of the penis allows for its several complex functions but also makes it particularly difficult to reconstruct in the setting of phalloplasty. Its general arrangement is that of a cylinder with two central corpora cavernosa bound together tightly by the tunica albuginea. Ventrally lies the corpus spongiosum, which encases the urethra. Overlying these structures is the deep penile fascia, or Buck's fascia, which tightly binds the corpus spongiosum and the corpora cavernosa into a single functioning entity. Buck's fascia also carries several neurovascular structures, including the deep dorsal veins, arteries, and nerves of the penis, the circumflex arteries and veins, and the penile lymphatics.

The glans is a vascular spongiosa which contains unique erogenous and tactile sensory nerve endings. The glans epithelium is distinct from that of the shaft and includes sensory cells, particularly around the corona. In an uncircumcised penis, the glans is protected by a bilaminar prepuce with an inner lamina consisting of uroepithelium similar to that of the glans and an outer lamina with glabrous skin similar to that of the shaft. Deep in the skin lies the superficial fascial system of the penis, or the Dartos fascia. This fascial layer is in continuation with Scarpa's fascia superiorly and Colles' fascia inferiorly.

\section{Vascular anatomy}

There are two distinct arterial systems that perfuse the penis - both of which are necessary to adequately perfuse the penis and all of its overlying skin ${ }^{[21]}$. The deep system originates from the internal pudendal arteries (branches of the internal iliac artery) that gives off perineal and scrotal branches before continuing as the common penile artery. Each common penile artery gives off three branches, the bulbar, urethral, and cavernosal, before terminating in the tortuous dorsal artery of the penis.

The superficial system originates from the external pudendal arteries, which are branches of the femoral artery. There are typically separate superficial and deep external pudendal arteries. The superficial supplies vascularity to the dartos fascia and genital skin, while the deep travels separately to further perfuse the dorsolateral and ventral shaft skin.

The venous drainage is similarly composed of two systems. A superficial system runs within the Dartos to drain the penile shaft skin, whereas the deep system drains the circumflex veins and deep dorsal veins into the prosthetic plexus and the crural and cavernosal veins into the internal pudendal veins.

\section{Sensation}

The nerves to the penis also arise from a dual source that run with the arteries. The dorsal penile nerves provide erogenous sensation but do not provide sensation to the penile shaft skin. The pudendal nerve 
is mixed motor, sensory, and autonomic, originating from the sacral roots S2 through S3 and is the main penile sensory nerve. The shaft is also innervated by ancillary erogenous nerves including the ilioinguinal nerves.

\section{GOALS OF RECONSTRUCTION}

In their 1987 article, Gilbert and Winslow ${ }^{[22]}$ described these five necessary criteria to achieve the ideal phallic reconstruction:

1. A reproducible procedure that takes place in one stage

2. Creation of a neourethra that facilitates voiding while standing

3. A phallus with erogenous and tactile sensibility

4. Sufficient bulk to permit the placement of a penile prosthesis, allowing for penetrative sexual intercourse

5. A satisfactory aesthetic result

These five goals must of course be weighed against donor site morbidity, as all techniques require the transfer of tissues from elsewhere in order to restore the missing skin, urethra, and soft tissue bulk. Meeting these criteria with conventional reconstructive options continues to challenge surgeons over thirty years later. In the sections that follow, we review each of the individual donor sites commonly employed in modern, conventional phalloplasty, assessing their ability to achieve these reconstructive goals.

\section{CONVENTIONAL SURGICAL TECHNIQUES}

At least at the surface, each of the conventional techniques for phalloplasty has the potential to achieve the above listed goals set forth by Gilbert and Winslow ${ }^{[22]}$ Ultimately, there are advantages and disadvantages to each flap, and therefore the choice of donor site should be a combination of both the individual patient's preference as well as the surgeon's ability to produce a consistent result.

\section{RFFF}

RFFF [Figure 1] is among the most common techniques for phalloplasty and considered by some to be the modern "gold standard" technique. The donor site is thin, pliable, and relatively hairless allowing for a flap that can be easily tubed and shaped with excellent aesthetic outcomes. The medial and lateral antebrachial cutaneous nerves can be coapted to the ilioinguinal and dorsal penile or clitoral nerves in order to provide excellent protective and erogenous sensation in most patients [Figure 2]. In transgender men, the clitoris can remain at the base of the phallus for stimulation as well. Technically, the radial artery of the flap can be anastomosed to several donor vessels including the profunda femoris, lateral circumflex femoral, circumflex iliac, or the inferior epigastric artery and their respective venae comitans. In some cases, the cephalic vein of the flap will also be included and anastomosed to a branch of the greater saphenous vein.

The technique for RFFF phalloplasty can be carried out in as many as 1-4 or more stages and depends on the needs of the patient and surgeon preference ${ }^{[3]}$. The first stage almost always involves the harvest and inset of the flap in the perineum. The flap is typically harvested from the non-dominant arm, with a portion of it used to form a narrow skin tube stented using a 16-French Foley catheter that is to function as the neourethra [Figure 3]. The donor site can often be very conspicuous due to the large amount of tissues required to create the neophallus. Donor site coverage is achieved with either a thick split or a full thickness skin graft at the time flap harvest [Figure 4], or in two stages with the initial application of an Integra Dermal Regeneration Template (Integra LifeSciences Corp., Princeton, NJ).

The aesthetics of the phallus can be refined by the creation of a corona using a local flap and a full thickness skin graft as described by Monstrey et al ${ }^{[23]}$ Although some surgeons perform this "glansplasty" at the 

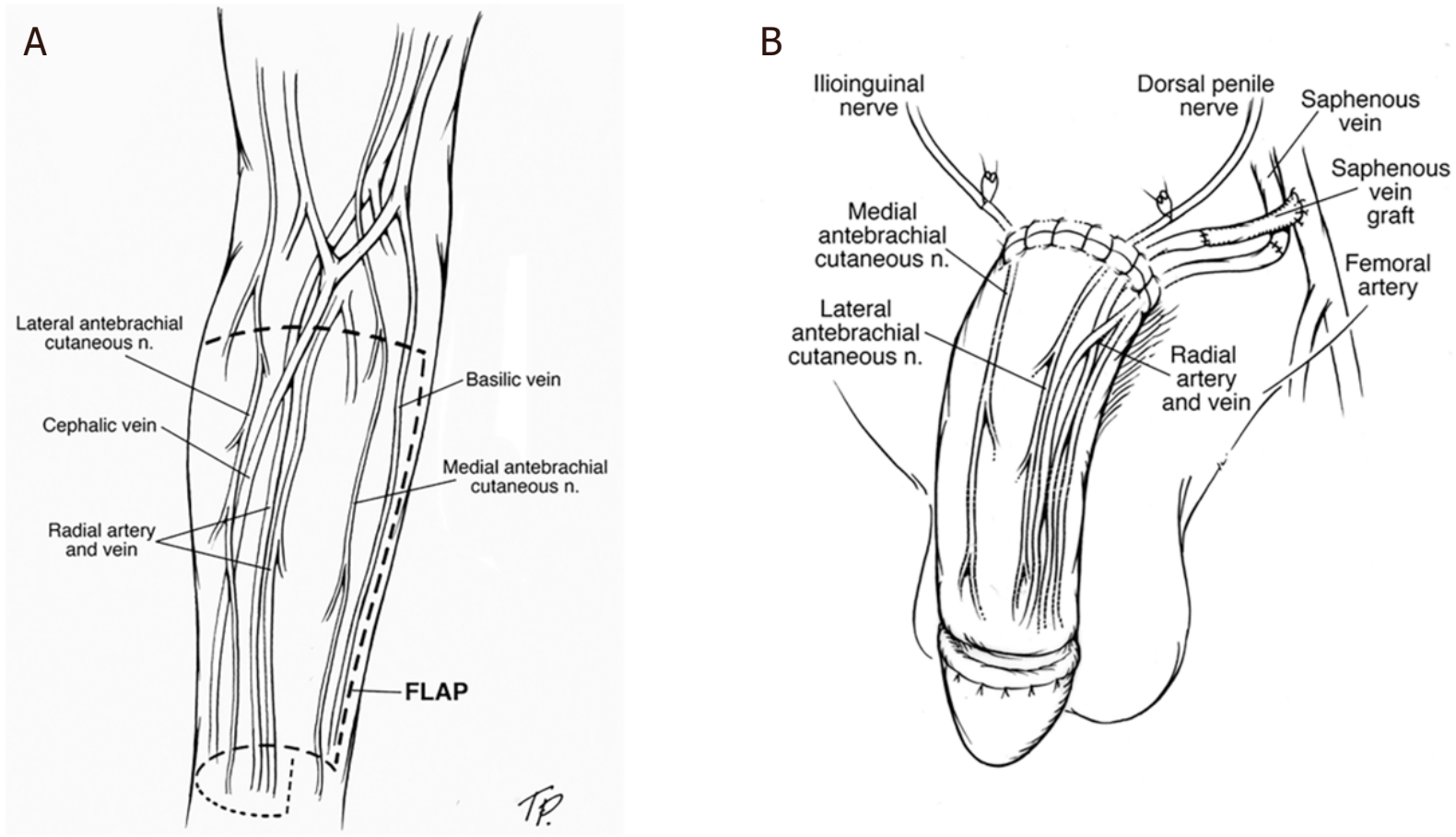

Figure 1. Outline of the radial forearm free flap phalloplasty on the arm. The flap is designed to include the lateral and medial antebrachial cutaneous nerves as well as the radial artery and veins and the cephalic vein (A); representation of the flap following inset (B)

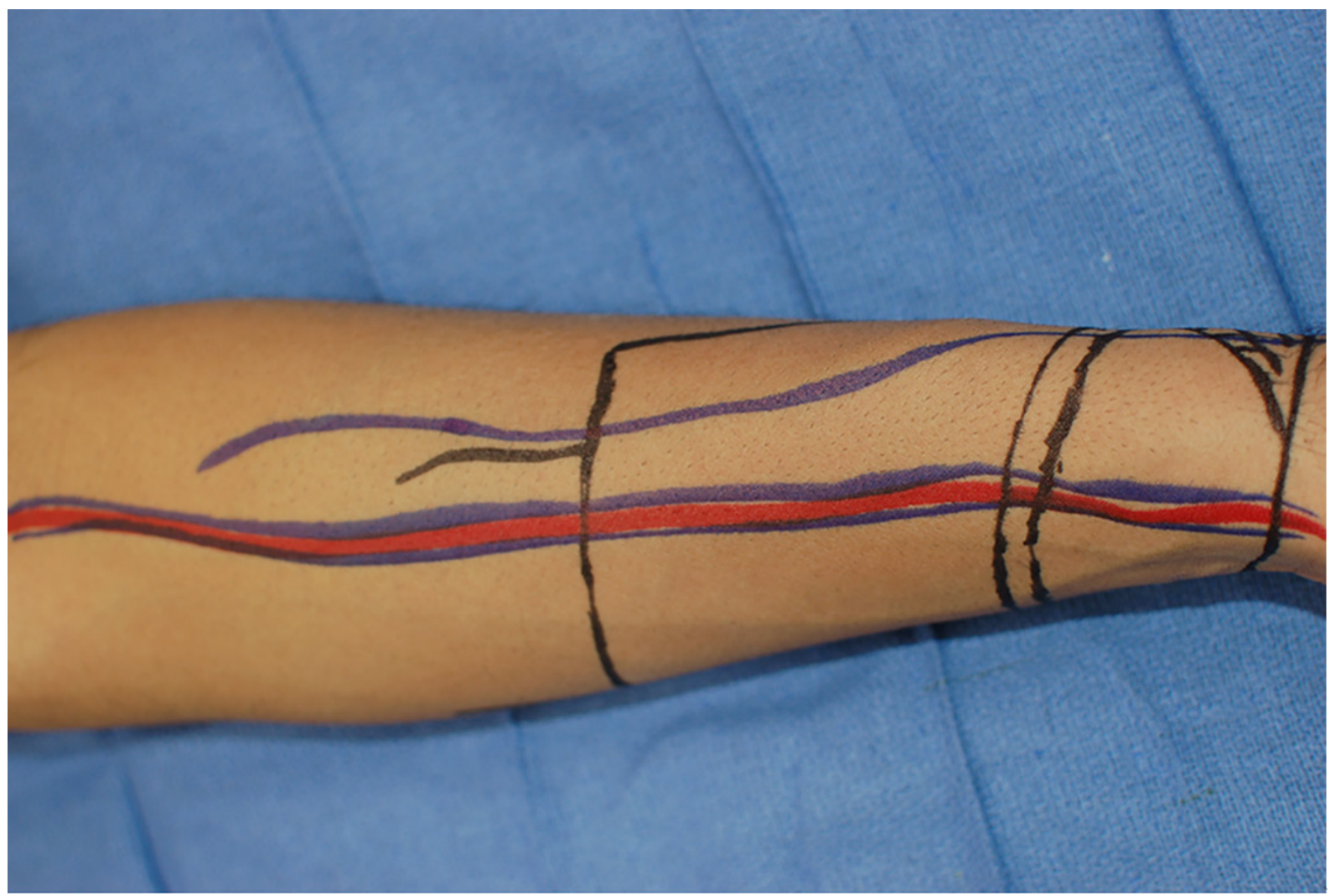

Figure 2. Markings of the radial forearm free flap in situ within the forearm. The outline of the flap, including the markings for glansplasty, is made in black. The courses of the radial artery (red) along with its two venae comitans (paired blue) and the cephalic vein (single blue) are marked out as well 

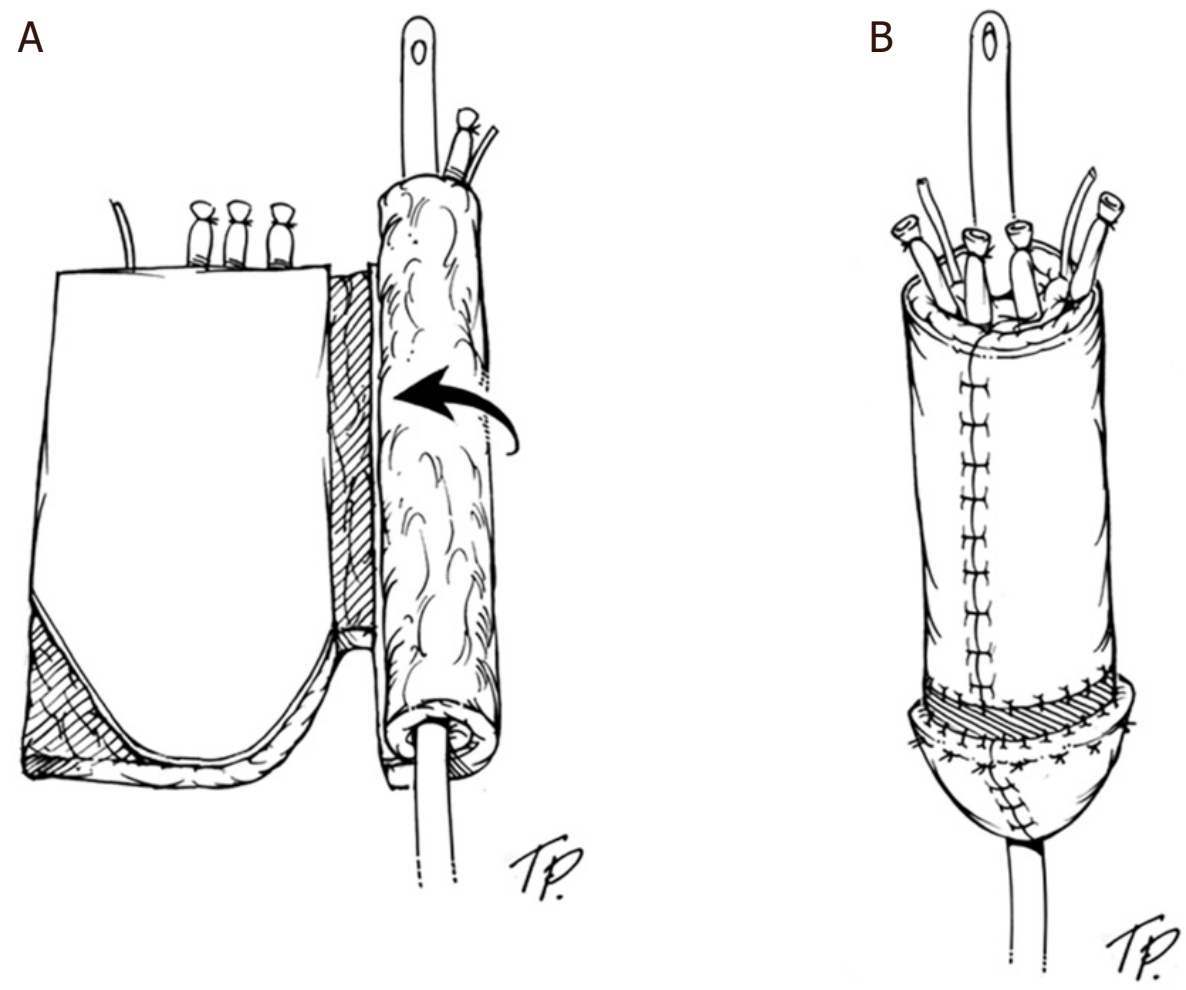

Figure 3. The flap is divided into three section prior to tubularization: the outer skin envelope of the neophallus; the de-epithelialized portion, which separates the skin and urethra; and the ulnar-sided skin paddle, which serves as the neourethra (A); the flap is tubularized over a 16-French Foley catheter (B)

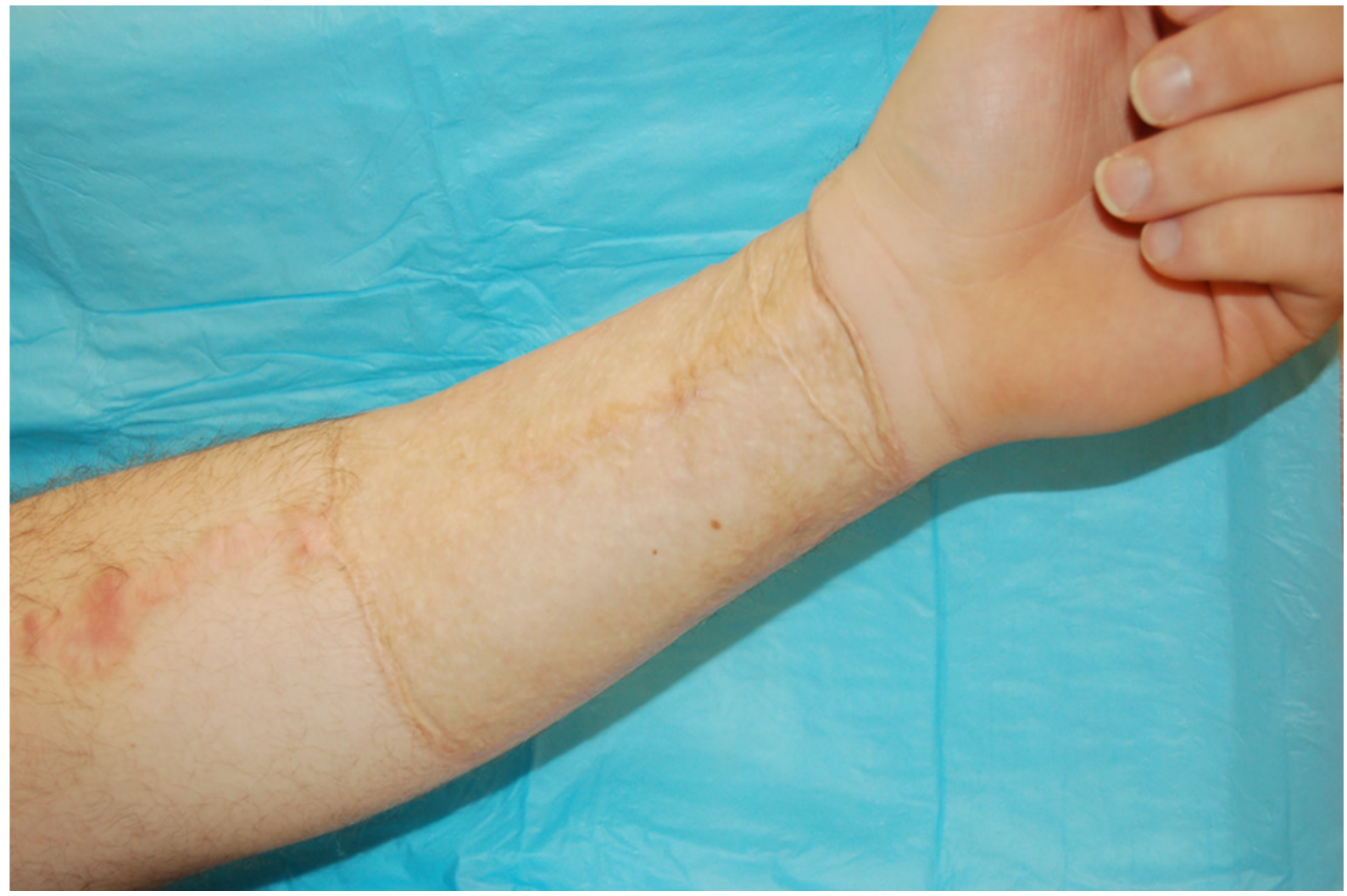

Figure 4. Well healed radial forearm donor site resurfaced with a thick split thickness skin graft at the time of flap harvest 


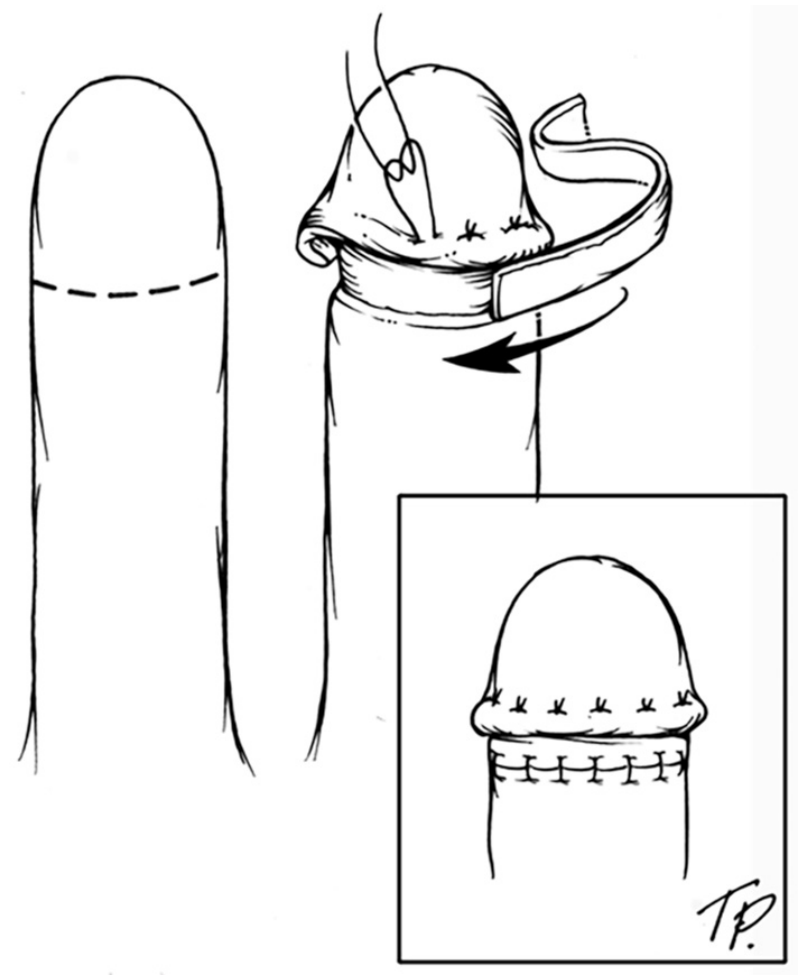

Figure 5. During the glansplasty, the distal flap is de-epithelized and curled onto itself to recapitulate the corona. A full thickness skin graft is harvested from the groin and placed below. Before the return of sensation to the neophallus, this can be further refined with tattooing if the patient so wishes once the wounds have healed

time of flap transfer, other will stage it for at least three months to allow the tissues to heal from the initial operation [Figure 5]. The corona can be further refined before the return of sensation by tattooing in order to match the color of the areola.

The anastomosis of the neourethra and native urethra may also vary in timing, from the time of flap transfer to a separate stage several months later. In many cases, the need to perform a urethral anastomosis is determined by the indication. For example, children with exstrophy may have a continent umbilical bladder stoma and not need urethral reconstruction. In these children, the native glans can be deepithelialized and brought out the ventral and proximal surface of the neophallus to allow for ejaculation from the native urethra. Without the normal peristalsis of the corpora bodies, the ejaculate may not reach the tip of the neophallus if a full-length urethra is constructed. Furthermore, the ability to urinate standing up may not be a priority for some transgender men, who may wish to forego urethral lengthening and anastomosis in order to avoid the relatively high complication rates.

The final stage of RFFF phalloplasty is typically the insertion of a penile prosthesis. This is normally performed up to one year after the index procedure in order to allow for adequate regeneration of protective sensation. Although some surgeons have described osteocutaneous modifications to RFFF in order to provide stiffness of the flap and avoid the need for a penile prosthesis, this procedure is associated with an increased risk of donor site fractures and not commonly employed ${ }^{[24,25]}$. Penile prostheses are discussed in further detail in a separate section below.

Overall, despite being the "gold standard" reconstructive technique [Figure 6], the outcomes of RFFF fall short in many ways. A recent meta-analysis by Yao et al. ${ }^{[3]}$ included 925 RFFF phalloplasties that included nearly $90 \%$ female-to-male gender-affirming surgeries. Although complications varied greatly based on the 

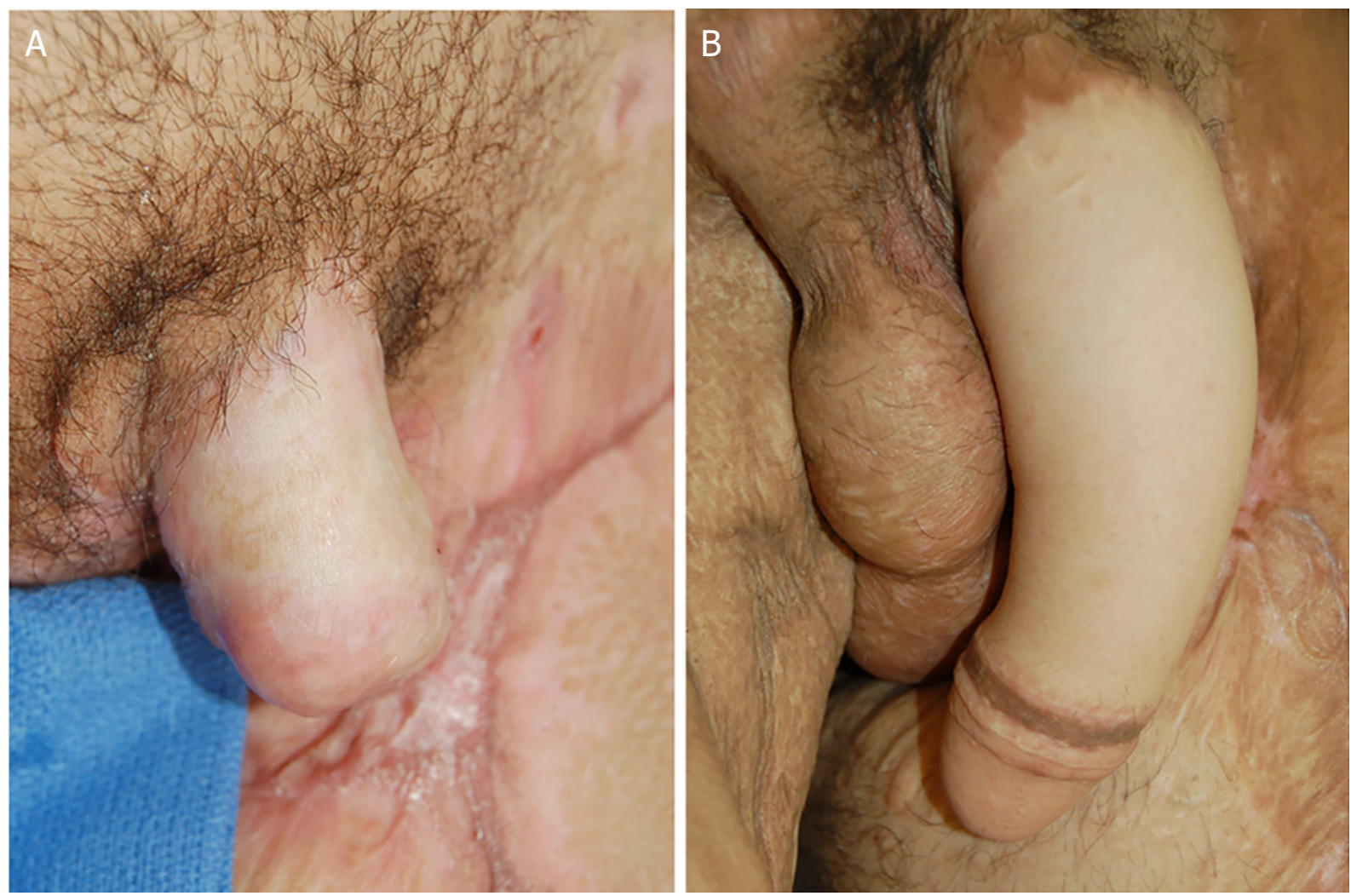

Figure 6. Before $(A)$ and after (B) images of a patient undergoing radial forearm free flap phalloplasty following partial amputation of the penis due to an improvised explosive device. The grafted skin just proximal to the corona can be tattooed to further refine the aesthetics of the neophallus

various technical modifications performed, total flap loss was rare with an incidence of $1.5 \%$, with another 7.4\% experiencing partial/distal flap loss. Urethral fistulas were much more common with an incidence of nearly $30 \%$ - of which $41 \%$ were able to be managed conservatively. Urethral strictures were less common and occurred in $8.2 \%$ of phalloplasties ${ }^{[3]}$. In one of the largest single center experiences with RFFF phalloplasties, Monstrey et al. ${ }^{[23]}$ reported similar outcomes with a $41 \%$ incidence of urologic complications and a $44 \%$ rate of penile prosthesis removal.

Nonetheless, patients tend to be happy with their RFFF reconstruction. As many as $75 \%-100 \%$ report the ability to void while standing, $97 \%$ are satisfied with cosmesis, and $87 \%$ of patients reported sensation in the neophallus ${ }^{[26]}$. With appropriate innervation, $80 \%$ of patients are able to achieve orgasm ${ }^{[27]}$.

\section{ALT}

The ALT flap [Figure 7], based on perforators of the descending branch of the lateral circumflex femoral vessels, can be used as both a pedicled and free flap for phalloplasty. Sensation to the flap is provided by the lateral circumflex femoral nerve. Some authors described harvesting an additional cuff of fascia with the flap that can be used to create a neo-tunica that will cover the eventual penile prosthesis ${ }^{[28]}$. Because of the bulk of the thigh subcutaneous tissues relative to the forearm, some surgeons do not arrange the flap in the "tube within a tube" configuration; instead, a separate skin graft is often harvested and wrapped around a catheter and sewn to the native urethra proximally. In thinner patients, a $1.5 \mathrm{~cm}$ strip can be deepithelialized and tabularized as in RFFF at the cost of a bulkier construct at the time of initial flap transfer. Other surgeons, including Mutaf and colleagues, have described a chimeric flap in which the skin perfused by the sartorius perforators is harvested and used to create the neourethra within the tubed ALT ${ }^{[29,30]}$. 


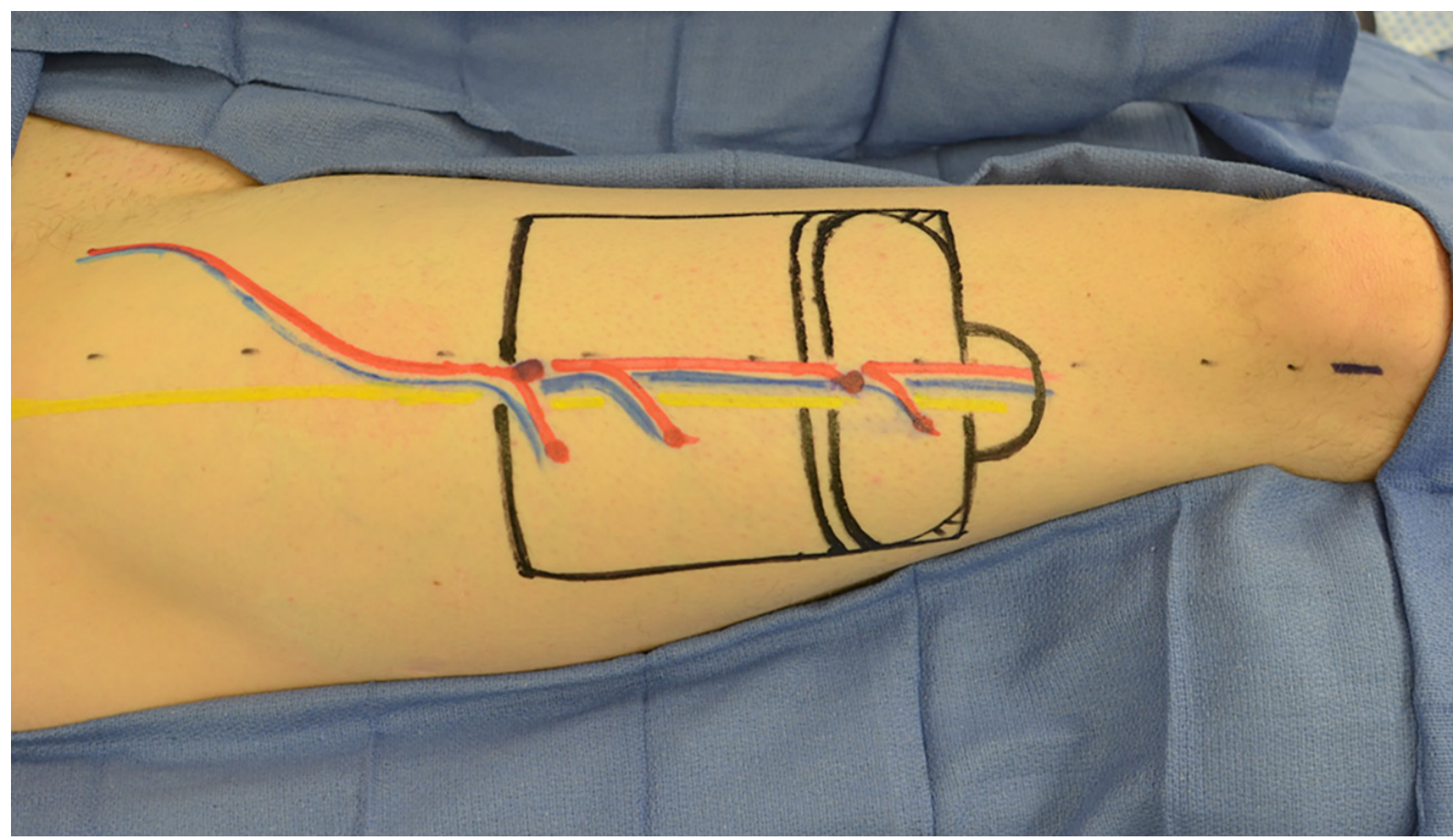

Figure 7. Markings of the ALT flap including glansplasty are made in black. The descending branch of the lateral femoral circumflex artery and its paired veins are marked in red and blue, respectively, along with the location of three perforators identified using Doppler ultrasonography. The course of the lateral femoral cutaneous nerve is depicted in yellow

Although technically more complex, this technique benefits from the use of vascularized tissue to form the urethral passage.

The pedicled ALT is a particularly powerful option in patients who have undergone several previous operations, such as in children with bladder exstrophy, patients who are very thin and RFFF would not provide enough bulk, or those in whom a free flap is relatively contraindicated. One of the major benefits of ALT is the relatively inconspicuous donor site location on the thigh that is more easily hidden than the forearm. Similar to RFFF, the number and timing of stages is typically dictated by patient needs and surgeon preference, and everything short of the penile prosthesis can theoretically be preformed in as few as one stage ${ }^{[30]}$. In all but the thinnest patients, however, debulking of the flap via serial excision and/or liposuction may be necessary in order to achieve an appropriately sized neophallus, and the vast majority of patients should be prepared for several stages before achieving an acceptable result.

Published functional and aesthetic results are relatively scarce and subject to a great deal of heterogeneity in surgical technique and outcomes [Figure 8]. Although complete flap loss is rare, particularly with the pedicled ALT, partial flap loss can occur in the periphery of the flap and in areas where the tissue has been folded. Limited patient reported outcomes studies have demonstrated that the vast majority of patients report satisfaction with the phallus and nearly two-thirds report the ability to urinate while standing and to undergo penetrative intercourse ${ }^{[31]}$. The most common complications are associated with the formation of urethral fistulas $(\sim 22 \%)$ and stricture/stenosis $(\sim 7 \%)^{[31]}$. Sensation in the ALT flap is generally considered to be good with coaptation of a dorsal penile/clitoral nerve to the lateral circumflex femoral nerve, with $100 \%$ of patients reporting at least sensation in the proximal half of the neourethra ${ }^{[3]}$.

\section{FOF}

FOF remains the most commonly used option that includes a vascularized boney component in order to allow for long-term rigidity without the need for a penile prosthesis. It also benefits from a relatively 

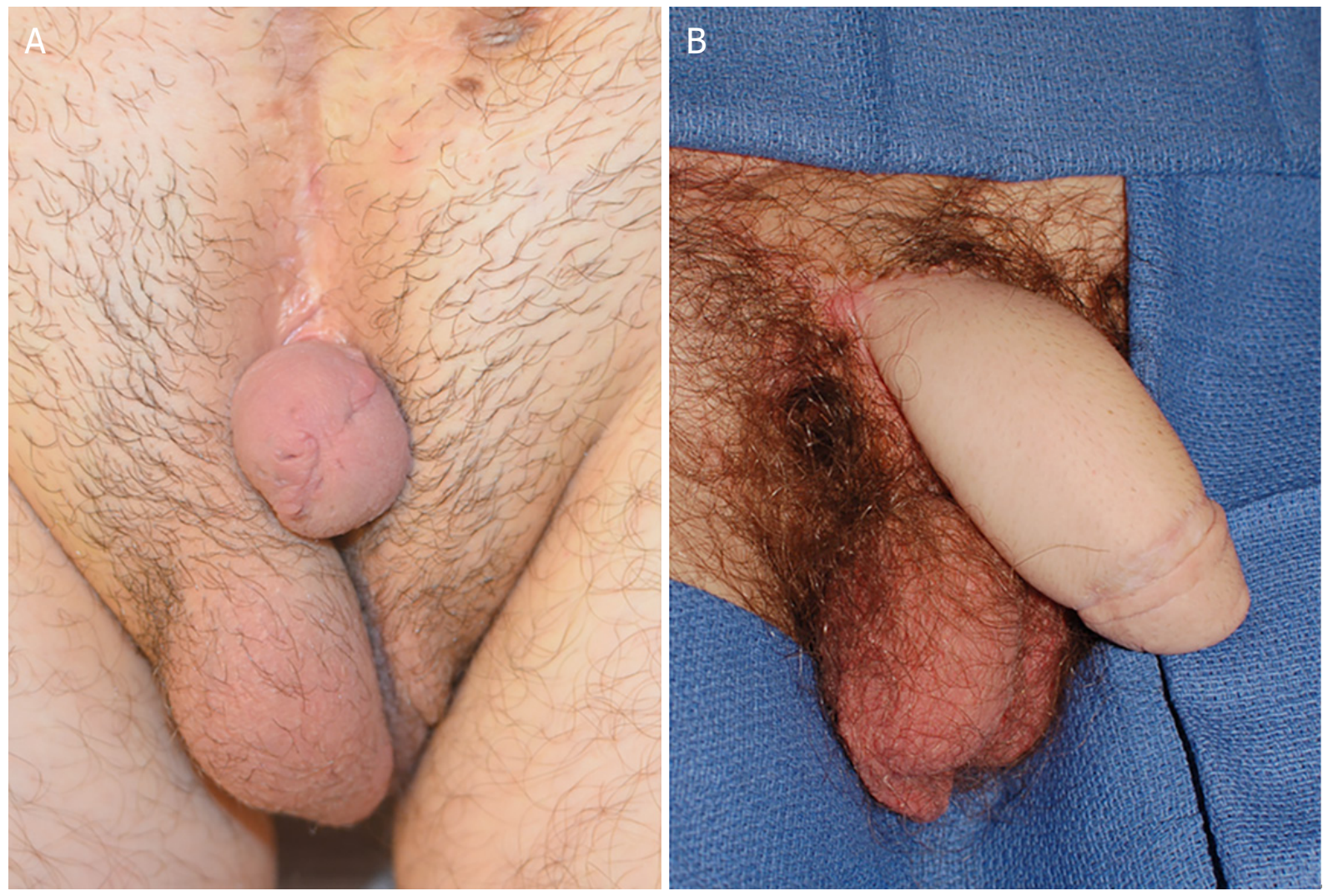

Figure 8. Before $(A)$ and after $(B)$ images of a patient undergoing anterolateral thigh flap phalloplasty

hidden donor site, while the primary disadvantages of FOF relate to potentially unpredictable bone resorption, risk for fracture, and the inability to modulate the stiffness of the neophallus, as with a penile prosthesis $^{[3]}$. Dabernig et al. ${ }^{[32]}$ described the use of a fasciocutaneous fibula flap without any bone in phalloplasty; although not typically employed in this fashion, this may represent one possible option in patients who wish to avoid the forearm donor site and in whom ALT is relatively contraindicated due to excessive subcutaneous tissue bulk. When the bone is included, it can be fixated proximally to either the penile corpora cavernosa or the pubic symphysis. Hage et al. ${ }^{[33]}$ suggested including a segment of bone $\sim 2 \mathrm{~cm}$ longer than the skin paddle so that the phallus is not floppy after fixation.

Because the tissues of the lower leg are relatively stiff and less amenable to rolling on itself, many authors report prelamination the neourethra with a skin graft in a separate stage before flap transfer. Urethral lengthening and/or anastomosis may occur in a separate third stage or at the time of flap transfer. As with most other flaps used in conventional penile reconstruction, FOF allows for phalloplasty in as few as one or as many as three or more stages. There is some evidence to suggest staging the procedure with prelamination of the neourethra reduces the incidence of urethral fistulas ${ }^{[33-35]}$.

Sensation to the flap is provided by coaptation of the donor nerves to the lateral sural cutaneous nerve, which lies posterior to the posterior crural intermuscular septum in nearly $75 \%$ of cases with an anterior branch in $26 \%{ }^{[36]}$. The nerve has been shown to be within $4 \mathrm{~cm}$ of the septum in $86 \%$ of cases; as such, we prefer to orient the skin paddle such that it is located posterior to the septum and in the proximal twothirds of the lower $\operatorname{leg}^{[35,36]}$. Although studies of sensation following FOF phalloplasty are very limited, Schaff and Papadopulos ${ }^{[37]}$ compared their patient reported outcomes to RFFF, demonstrating potentially worse sensibility with FOF. 
Overall, the published outcomes of the fibula are not dissimilar from the other flaps discussed and largely suffer from the same limitations mentioned above. Flap loss, either complete or partial, range in the $1 \%-2 \%$ and $10 \%-15 \%$ ranges, respectively ${ }^{[3]}$. Urethral fistula formation remains the most commonly reported complication, followed by urethral strictures ${ }^{[3]}$. Nonetheless, the majority of patients report that they are able to urinate standing up, partake in sexual intercourse, and that they are satisfied with their overall result ${ }^{[3,37,38]}$.

\section{LDMF}

Perovic and colleagues have reported extensively on the use of LDMF in phalloplasty with excellent results $^{[39,40]}$. The advantages of this donor site include its well concealed location, ability to be closed primarily in most situations, relatively hairless donor site, and a large amount of tissues allowing for an aesthetic reconstruction. Owing to the less sensitive nature of the back skin, however, there are concerns that erogenous sensation may be relatively difficult to achieve with LDMF. The flap is based on the thoracodorsal vessels and nerve. Typically, only a thin strip of muscle around the pedicle is harvested in order to minimize donor site morbidity. As described by Perovic, reconstruction with LDMF takes place in several stages including flap harvest and creation of the neophallus, two stages of urethroplasty using a buccal mucosa inlay, and finally the insertion of a penile prosthesis. Muscle sparing thoracodorsal artery perforator flaps have also been described in phalloplasty ${ }^{[41]}$, as well as other perforator flaps based on the subscapular vessel system including the scapular and parascapular flaps ${ }^{[3,42,43]}$.

Limited outcomes studies have demonstrated largely similar complication rates with LDMF as with other options for phalloplasty. Although urethral fistula and stricture rates have not been rigorously studied, they are believed to be largely on the same order of magnitude as other reconstructive options ${ }^{[3]}$. Two unique complications to consider with the use of the back as a donor site are a potentially increased risk of hematoma and/or seroma at the donor site. Although the majority of the muscle is open spared, minimizing the amount of dead space at the back, the need to widely undermine the skin in order to achieve primary closure can may result in blood or fluid collections in as many as $10 \%$ of patients ${ }^{[3]}$. Patients who received LDMF may also experience the phenomenon of "paradox erection," in which muscle contraction results in stiffening of the neophallus, potentially allowing for penetrative intercourse ( $82 \%$ of patients in one study) ${ }^{[44]}$. Otherwise, protective sensation has been noted in the proximal neophallus for up to two years after surgery, and patients generally report the ability to void while standing and satisfaction with flap aesthetics ${ }^{[4]}$.

\section{Penile prosthesis}

The rigidity required for penetrative intercourse is an important component of a successful phalloplasty, however it is to date impossible to adequately reconstruct the erectile tissues of the penis using autologous tissue. As discussed above, the osteocutaneous fibula flap attempts to address this need by incorporating a length of bone to provide rigidity to the neophallus. This is far from the ideal solution, however, as the bone remains permanently erect and the osseous component is susceptible to warping, fracture, and unpredictable resorption.

As such, the hydraulic erectile implant has become the standard at many centers across the world ${ }^{[3,19,45]}$. These implants are typically placed no less than 6-12 months following the completion of reconstruction once the wounds have completely healed, protective sensation is fully restored, and the phallus is at its final size. The prosthesis is often left semi-inflated for one or more weeks to enable capsule formation around the cylinder. After the incisions have healed the implant may be inflated to create an erection and deflated at other times as needed. 
Although a key component of a successful phalloplasty, the penile prosthesis is unfortunately also the portion of reconstruction with one of the highest rates of complication. The rate of explanation is over $40 \%$ in most large series ${ }^{[22,45]}$, and most often secondary to infection, erosion of the overlying soft tissues, or device dysfunction. The absence of a tunica albuginea is believed to predispose the device to trauma and erosion when compared to the use of these devices to treat impotence, leading some authors to fabricate a neo-tunica using vascularized fascia lata to protect the device ${ }^{[28,46]}$. Despite these drawbacks, over $80 \%$ of patients with prosthesis report satisfactory sexual intercourse ${ }^{[47]}$. This is undoubtedly an important area of ongoing research that requires additional long-term follow-up and innovation moving forward.

\section{PENILE TRANSPLANTATION}

\section{History}

Some of the earliest animal models for penile transplantation were developed in the early 2000 s. The feasibility of allogeneic penile transplantation through nonvascular anastomosis and later arterial anastomosis to the distal corpus spongiosum were first demonstrated in a rat model ${ }^{[48,49]}$. Autotransplantation rat models have also been developed to evaluate the viability and functionality of re-planted phalluses $^{[50]}$. Since then, several advancements including a canine model ${ }^{[51]}$, deceased donor anatomic studies $^{[21]}$, and an ex vivo model to assess graft rejection and its effect on erectile function have helped to bridge the gap between research and practice in preparation for the first few cases of penile transplantation across the globe ${ }^{[52]}$.

The first in human penile transplantation was attempted in 2006 in China. A 44-year-old man who had sustained a traumatic injury underwent a technically successful procedure, however the graft was explanted after two weeks due to psychological rejection ${ }^{[10]}$. In 2015 , the first successful penis transplant was performed in South Africa on a 21 -year-old man with a penile injury sustained during cultural circumcision $^{[9]}$. Two years following this procedure, the recipient reported the ability to urinate and to achieve erections, orgasms, and ejaculation ${ }^{[53]}$. In 2017, the same group in South Africa performed its second penis transplantation ${ }^{[54]}$. In the United States, a partial penis transplant from a deceased donor to a 64-year-old man following oncologic amputation was performed in $2016^{[8]}$. Six months following the operation, the patient had recovered sensation, was voiding successfully, and reported partial erectile function. Finally, in 2018, the entire penis, scrotum, and part of the abdominal wall were transplanted from a deceased donor to a patient who had sustained a blast injury to the abdominal wall and perineum. One year postoperatively, the patient is voiding successfully and has return of erogenous sensation and the ability to obtain a full erection [Figure 9]. Most importantly, he reports that his transplanted penis feels "normal"

\section{Indications}

Most discussions on the use of penis transplantation have focused on traumatic etiologies. In this context, extremity amputation or injuries may compromise reconstructive donor sites, precluding conventional options for phalloplasty. That said, the lack of conventional reconstructive options is not alone an indication for penis transplantation. Traditionally, penile transplantation has been considered a last resort after several failed attempts at phalloplasty ${ }^{[16]}$. This thought process has been recently questioned within the literature, as there are considerable downsides to undergoing several failed reconstructive attempts before transplantation $^{[55]}$.

We believe that surgeons should preserve conventional reconstructive options as a contingency plan in the event of allograft failure. There are several benefits to pursuing transplantation before exhausting options for phalloplasty. First, the superior functional and cosmetic outcomes of transplantation may outweigh its associated risks for certain patients. Furthermore, there may be no appropriate salvage options available for 

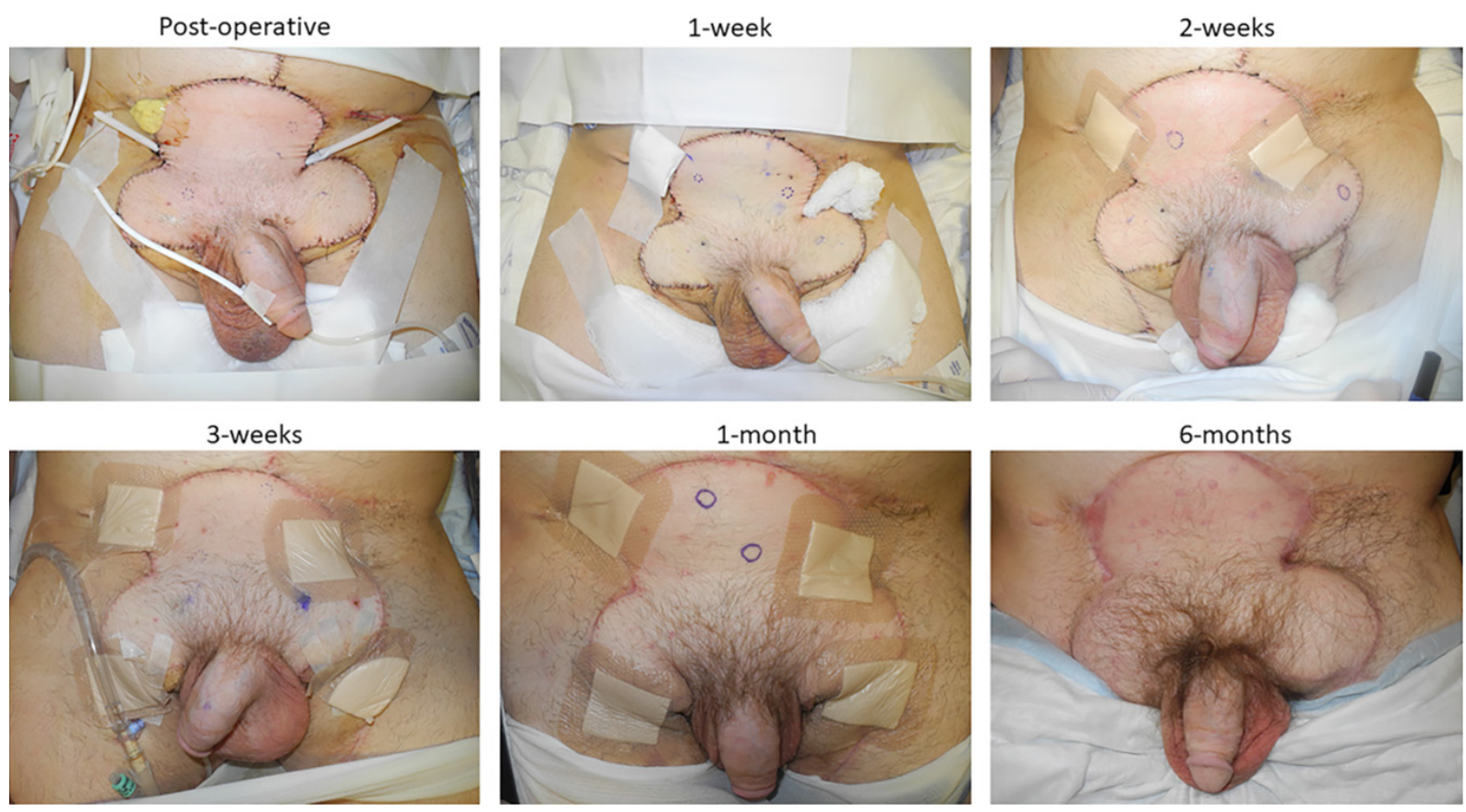

Figure 9. Clinical images following total penis, scrotum, and lower abdominal wall transplantation over the course of six months postoperatively. Circular scars at biopsy sites can be appreciated on the skin of the abdomen and groin. The graft healed uneventfully and has incorporated well without evidence of rejection

penile reconstruction if the transplant were to fail. Finally, without long-term data on graft longevity, we should make sure to preserve several "back-up" reconstructive options.

\section{Patient selection}

The allocation of life-enhancing grafts, including penile transplants, should follow the standard practices used for life-saving transplantation: the resource is allocated based on equity, priority, and net benefit ${ }^{[56]}$.

The ethical and practical challenges of penis transplantation in a child have thus far limited the procedure to adults ${ }^{[57,58]}$. The cumulative risks of a transplant are greater in children than adults due to the extended exposure to immunosuppression over their lifetime. Additionally, adherence to immunosuppressive regimens may also prove challenging in children, particularly during the adolescent period. Furthermore, it is not clear when a child can provide adequate consent to such a life altering procedure, and parental permission may not be sufficient ethically given the circumstances. Third, pediatric penile transplant is complicated by issues related to donor matching. It would not be appropriate to transplant an adult phallus onto a child, but the alternative of using an age-congruent phallus risks issues later in adulthood because of an age-incongruent phallus. Finally, we do not currently know what a reasonable lifespan for a penis transplant is, and childhood recipients would likely require another transplant in adulthood. As such, conventional reconstruction should remain the mainstay for these children until an appropriate decision regarding transplantation can be made in adulthood.

The majority of transplants to date were performed for traumatic indications, however oncologic extirpation remains another important avenue for potential transplantation. We have expanded our eligibility criteria to include patients with a five-year history of remission following oncologic penectomy. The largest study to date on recurrence in penile cancer reported that all local and distant recurrences occur within a five-year window following initial resection ${ }^{[59]}$. Furthermore, most local recurrences occurred after penile preserving treatment. Given that all remaining native penile skin can be resected before transplantation, the risk of 
locoregional recurrence should be negligible. We also believe that criteria for transplantation should be expanded to include men with congenitally ambiguous genitalia or true micropenis. To date, even the most sophisticated techniques for conventional penile reconstruction are fraught with urinary complications and issues related to penile prosthesis ${ }^{[3,19]}$. Although there are greater risks with penis transplantation, this may be outweighed by the improved function and aesthetics of transplanted phallus. At this time, further deliberation on the use of penile transplantation in transgender men is needed as the lack of proximal corpora would preclude the ability to achieve an erection with the transplanted penis.

\section{Technical considerations}

\section{Donor selection}

Limited donor availability represents a major hurdle for any kind of transplantation ${ }^{[60]}$. In addition to HLA matching and screening for a healthy donor phallus that is without vascular disease, sexually transmitted infection, and/or complications of diabetes, attention should be paid to recipient aesthetic preferences. The appearance of donor phallus must be inline with the recipient's desired appearance and discussed frankly before listing, in an attempt to limit psychological stresses.

\section{Surgical planning}

Given the anatomical complexity, penile transplantation presents unique challenges including how proximally the graft will need to be harvested. Anastomosing a distal portion of the penis requires fewer structural anastomoses than transplantation of the entire penis with portions of the pelvic floor. Larger grafts may be required to address wartime injuries when extensive damage to the genitalia, pelvic floor, and abdominal tissues can occur from the upward blast of an improvised explosive device. In congenital anomalies, there may be insufficient tissue development to provide adequate proximal corpora to be anastomosed.

The penis has three main vascular perfusion territories that have been previously described in detail ${ }^{[21]}$. The first includes the shaft skin, which is perfused by the external pudendal arteries bilaterally. The second territory includes the glans and corpus spongiosum, which are supplied by the dorsal arteries. Finally, the corpora cavernosa are perfused by the cavernous arteries. The dorsal and cavernous arteries both originate from the internal pudendal artery. However, depending on the level of the penis transplantation, each may require its own vascular anastomosis ${ }^{[29]}$. Venous outflow similarly depends upon the extent of graft required. In a mid-shaft transplantation, this could be limited to as little as the deep and superficial dorsal veins, whereas, in the most extensive penis, scrotum, and abdominal wall transplantation performed to date, the dorsal veins were anastomosed in addition to the bilateral saphenous veins ${ }^{[7]}$. Similar to replantation, the donor dorsal penile nerves can be coapted with the recipient dorsal penile nerves, and the donor urethra anastomosed with the recipient urethra in a spatulated fashion. The tunica albuginea, Buck's fascia, and dartos fascia are also connected in addition to the skin between donor and recipient tissues.

\section{Postoperative care}

Postoperatively, transplant recipients must have access to the appropriate monitoring to minimize both medical and psychological risks. Psychological counselling should begin during the pre-transplant workup and be continued afterward to ensure that the patient integrates the graft with their sense of identity. Certain sexually transmitted infections may be particularly devastating to the graft within the context of systemic immunosuppression, and safe sex counselling is essential to the patient's long-term safety. Given the intimate nature of penile transplants, sexual partners should also be involved in care if the recipient so wishes. Relationship counselling provides an opportunity to ensure that the recipient has a stable support network to assist with the necessary emotional adjustments and can also be an essential component of these patients' care. 
Our preference for perioperative antibacterial prophylaxis is intravenous piperacillin/tazobactam $3.375 \mathrm{~g}$ prior to and during the operation. Prophylaxis is continued with cefazolin $2 \mathrm{~g}$ IV every $8 \mathrm{~h}$ for additional three days. For antiviral prophylaxis, we use valacyclovir $500 \mathrm{mg}$ twice daily for 12 months. Testing is performed for herpes simplex virus I/II, varicella zoster virus, Epstein-Barr virus, and cytomegalovirus, and prophylaxis can be adjusted as needed based on these results. Pneumocystis prophylaxis is with daily trimethoprim-sulfamethoxazole $400 \mathrm{mg} / 80 \mathrm{mg}$ for a total of 12 months. Anti-candida prophylaxis is with fluconazole $800 \mathrm{mg}$ loading dose followed by $400 \mathrm{mg}$ daily for one month.

Immunosuppression regimens vary from one center to the other. At our center, a recipient is treated with an immunomodulatory regimen consisting of monoclonal antibody induction, calcineurin inhibitor (tacrolimus) monotherapy maintenance, and a donor bone marrow cell infusion.

\section{Outcomes}

Successful urinary transport is generally achieved in penis transplantation. This is not surprising given the high success rates with replantation and primary anastomotic urethroplasties where two segments of healthy urethra are reapproximated. This is unlike phalloplasty, where tubularized skin is used to create a neourethra, allowing for the high complication rates discussed above. Several case series have demonstrated that it is possible to obtain natural erections after penile replantation ${ }^{[61]}$. Thus far, the experience has been similar with the limited series of penile transplantations ${ }^{[7]}$. Furthermore, at one year postoperatively, the most recent patient who received the most extensive penile transplantation to date reports the ability to achieve orgasm, as well as substantial improvements in pleasure scores on patient-reported outcome measures $^{[7]}$.

\section{CONCLUSION}

Over 30 years after Gilbert and Winslow ${ }^{[22]}$ outlined the five criteria to achieve ideal phallic reconstruction, the surgical community has finally realized this objective. Although conventional techniques including RFFF, ALT, FOF, and LDMF have gained popularity as common flaps used in penile reconstruction, these procedures are often fraught with complications and require multiple stages and revisions before achieving an acceptable result. Penile transplantation represents a single-stage procedure that allows the recipient to void while standing, provides protective and erogenous sensation as well as the ability to achieve an erection, and results in an unmatched aesthetic outcome [Figures 2, 8, and 9].

\section{DECLARATIONS}

\section{Authors' contributions}

Made substantial contributions to conception, design, and execution of the review: Khavanin N, Redett RJ

\section{Availability of data and materials}

All data and materials used in the current article are available from the corresponding author upon request.

\section{Financial support and sponsorship}

None.

\section{Conflicts of interest}

Both authors declared that there are no conflicts of interest.

\section{Ethical approval and consent to participate}

The Johns Hopkins School of Medicine Penile transplantation protocol has been reviewed and approved by the Institutional Review Board. All participants of the program undergo extensive medical and psychosocial 
screening and provide explicit written informed consent for study participation. Study procedures are performed in accordance to the Declaration of Helsinki.

\section{Consent for publication}

All individuals whose personal data were included within this review provided explicit written consent for publication of these data.

\section{Copyright}

(c) The Author(s) 2020.

\section{REFERENCES}

1. Bogoraz N. On complete plastic reconstruction of a penis sufficient for coitus. Sov Surg 1936;8:303-9.

2. Gillies SH, Harrison R. Congenital absence of the penis. Br J Plast Surg 1948;1:8-28.

3. Yao A, Ingargiola MJ, Lopez CD, Sanati-Mehrizy P, Burish NM, et al. Total penile reconstruction: a systematic review. J Plast Reconstr Aesthet Surg 2018;71:788-806.

4. Kropp B, Cohn JE, Wang W, Sokoya M, Ducic Y. Free tissue transfer penile reconstruction. Semin Plast Surg 2019;33:24-9.

5. Salmerón-González E, Simón-Sanz E, García-Vilariño E, Sánchez-García A, Pérez-García A, et al. Technical detail on nerve coaptation in phalloplasty: use of fibrin glue instead of sutures. Sex Med Rev 2019;7:376.

6. Massanyi EZ, Gupta A, Goel S, Gearhart JP, Burnett AL, et al. Radial forearm free flap phalloplasty for penile inadequacy in patients with exstrophy. J Urol 2013;190:1577-82.

7. Redett RJ 3rd, Etra JW, Brandacher G, Burnett AL, Tuffaha SH, et al. Total penis, scrotum, and lower abdominal wall transplantation. N Engl J Med 2019;381:1876-8.

8. Cetrulo CL Jr, Li K, Salinas HM, Treiser MD, Schol I, et al. Penis transplantation: first US experience. Ann Surg 2018;267:983-8.

9. Bateman C. World's first successful penis transplant at Tygerberg Hospital. S Afr Med J 2015;105:251-2.

10. Hu W, Lu J, Zhang L, Wu W, Nie H, et al. A preliminary report of penile transplantation: part 2. Eur Urol 2006;50:1115-6; discussion 1116.

11. Hu W, Lu J, Zhang L, Wu W, Nie H, et al. A preliminary report of penile transplantation. Eur Urol 2006;50:851-3.

12. Siegel RL, Miller KD, Jemal A. Cancer statistics, 2018. CA Cancer J Clin 2018;68:7-30.

13. Ornellas AA. Management of penile cancer. J Surg Oncol 2008;97:199-200.

14. Pow-Sang MR, Ferreira U, Pow-Sang JM, Nardi AC, Destefano V. Epidemiology and natural history of penile cancer. Urology 2010;76:S2-6.

15. Hudak SJ, Morey AF, Rozanski TA, Fox CW Jr. Battlefield urogenital injuries: changing patterns during the past century. Urology 2005;65:1041-6.

16. Tuffaha SH, Cooney DS, Sopko NA, Bivalacqua TJ, Lough DM, et al. Penile transplantation: an emerging option for genitourinary reconstruction. Transpl Int 2017;30:441-50.

17. Janak JC, Orman JA, Soderdahl DW, Hudak SJ. Epidemiology of genitourinary injuries among male U.S. service members deployed to iraq and afghanistan: early findings from the trauma outcomes and urogenital health (TOUGH) project. J Urol 2017;197:414-9.

18. The Williams Institute. How many adults identify as transgender in the United States? Available from: https://williamsinstitute.law.ucla. edu/wp-content/uploads/How-Many-Adults-Identify-as-Transgender-in-the-United-States. [Last accessed on 5 Aug 2020]

19. Bluebond-Langner R, Redett RJ. Phalloplasty in complete aphallia and ambiguous genitalia. Semin Plast Surg 2011;25:196-205.

20. Gearhart JP, Mathews R. Exstrophy-epispadias complex. In: Wein AJ, Kavoussi LR, Novick AC, Partin AW, Peters CA, editors. Campbell-Walsh Urology. 9th ed. Philadelphia: Saunders; 2007. pp. 3497-555.

21. Tuffaha SH, Sacks JM, Shores JT, Brandacher G, Lee WP, et al. Using the dorsal, cavernosal, and external pudendal arteries for penile transplantation: technical considerations and perfusion territories. Plast Reconstr Surg 2014;134:111e-9.

22. Gilbert DA, Winslow BH. Penis construction. Semin Urol 1987;5:262-9.

23. Monstrey S, Hoebeke P, Selvaggi G, Ceulemans P, Van Landuyt K, et al. Penile reconstruction: is the radial forearm flap really the standard technique? Plast Reconstr Surg 2009;124:510-8.

24. Satteson ES, Satteson AC, Waltonen JD, Li Z, Wiesler ER, et al. Donor-site outcomes for the osteocutaneous radial forearm free flap. J Reconstr Microsurg 2017;33:544-8.

25. Biemer E. Penile construction by the radial arm flap. Clin Plast Surg 1988;15:425-30.

26. Garaffa G, Raheem AA, Christopher NA, Ralph DJ. Total phallic reconstruction after penile amputation for carcinoma. BJU Int 2009;104:852-6.

27. Ma S, Cheng K, Liu Y. Sensibility following innervated free radial forearm flap for penile reconstruction. Plast Reconstr Surg 2011;127:235-41.

28. Rubino C, Figus A, Dessy LA, Alei G, Mazzocchi M, et al. Innervated island pedicled anterolateral thigh flap for neo-phallic reconstruction in female-to-male transsexuals. J Plast Reconstr Aesthet Surg 2009;62:e45-9.

29. Mutaf M. A new surgical procedure for phallic reconstruction: istanbul flap. Plast Reconstr Surg 2000;105:1361-70. 
30. Mutaf M, Isik D, Bulut O, Büyükgüral B. A true one-stage nonmicrosurgical technique for total phallic reconstruction. Ann Plast Surg 2006;57:100-6.

31. Morrison SD, Shakir A, Vyas KS, Kirby J, Crane CN, et al. Phalloplasty: a review of techniques and outcomes. Plast Reconstr Surg 2016;138:594-615.

32. Dabernig J, Chan LK, Schaff J. Phalloplasty with free (septocutaneous) fibular flap sine fibula. J Urol 2006;176:2085-8.

33. Hage JJ, Winters HAH, Van Lieshout J. Fibula free flap phalloplasty: modifications and recommendations. Microsurgery 1996;17:358-65.

34. Capelouto CC, Orgill DP, Loughlin KR. Complete phalloplasty with a prelaminated osteocutaneous fibula flap. J Urol 1997;158:2238-9.

35. Christiano JG, Dorafshar AH, Rodriguez ED, Redett RJ. Repair of recurrent cleft palate with free vastus lateralis muscle flap. Cleft Palate Craniofac J 2012;49:245-8.

36. Woerdeman LAE, Chaplin BJ, Griffioen FMM, Bos KE. Sensate osteocutaneous fibula flap: anatomic study of the innervation pattern of the skin flap. Head Neck 1998;20:310-4.

37. Schaff J, Papadopulos NA. A new protocol for complete phalloplasty with free sensate and prelaminated osteofasciocutaneous flaps: experience in 37 patients. Microsurgery 2009;29:413-9.

38. van Rooij JC, Plomp R. The effect of linguistic entropy on speech perception in noise in young and elderly listeners. J Acoust Soc Am 1991;90:2985-91.

39. Djordjevic ML, Bumbasirevic MZ, Vukovic PM, Sansalone S, Perovic SV. Musculocutaneous latissimus dorsi free transfer flap for total phalloplasty in children. J Pediatr Urol 2006;2:333-9.

40. Perovic SV, Djinovic R, Bumbasirevic M, Djordjevic M, Vukovic P. Total phalloplasty using a musculocutaneous latissimus dorsi flap. BJU Int 2007;100:899-905; discussion 905.

41. Lugo-Fagundo C, Ahn H, O’Brien-Coon D, Fishman EK. The role of cinematic rendering in pre-operative planning of a thoracodorsal artery perforator flap (TDAP) phalloplasty: a case study. BJR Case Rep 2019;5:20180084.

42. Djordjevic ML. Novel surgical techniques in female to male gender confirming surgery. Transl Androl Urol 2018;7:628-38.

43. Dong L, Dong Y, He L, Liu C, Zhang Z, et al. Penile reconstruction by preexpanded free scapular flap in severely burned patient. Ann Plast Surg 2014;73 Suppl 1:S27-30.

44. Ranno R, Veselý J, Hýza P, Stupka I, Justan I, et al. Neo-phalloplasty with re-innervated latissimus dorsi free flap: a functional study of a novel technique. Acta Chir Plast 2007;49:3-7.

45. Hoebeke PB, Decaestecker K, Beysens M, Opdenakker Y, Lumen N, et al. Erectile implants in female-to-male transsexuals: our experience in 129 patients. Eur Urol 2010;57:334-40.

46. Garaffa G, Raheem AA, Ralph DJ. An update on penile reconstruction. Asian J Androl 2011;13:391-4.

47. Monstrey SJ, Ceulemans P, Hoebeke P. Sex reassignment surgery in the female-to-male transsexual. Semin Plast Surg 2011;25:229-44.

48. Sonmez E, Nasir S, Siemionow M. Penis allotransplantation model in the rat. Ann Plast Surg 2009;62:304-10.

49. Koga H, Yamataka A, Wang K, Kato Y, Lane GJ, et al. Experimental allogenic penile transplantation. J Pediatr Surg 2003;38:1802-5.

50. Akyurek M, Ozkan O, Safak T, Ozgentas HE, Dunn RM. The penile flap in the rat: description and autotransplantation. Ann Plast Surg 2005;55:94-100; discussion 101.

51. Zhao Y, Hu W, Zhang L, Guo F, Wang W, et al. Penis allotransplantation in beagle dog. Biomed Res Int 2016;2016:1489204.

52. Sopko NA, Matsui H, Lough DM, Miller D, Harris K, et al. Ex vivo model of human penile transplantation and rejection: implications for erectile tissue physiology. Eur Urol 2017;71:584-93.

53. van der Merwe A, Graewe F, Zühlke A, Barsdorf NW, Zarrabi AD, et al. Penile allotransplantation for penis amputation following ritual circumcision: a case report with 24 months of follow-up. Lancet 2017;390:1038-47.

54. Ngaage LM, Elegbede A, Sugarman J, Nam AJ, Cooney CM, et al. The baltimore criteria for an ethical approach to penile transplantation: a clinical guideline. Transpl Int 2020;33:471-82.

55. Diaz-Siso JR, Borab ZM, Plana NM, Parent B, Stranix JT, et al. Vascularized composite allotransplantation: alternatives and catch-22s. Plast Reconstr Surg 2018;142:1320-6.

56. Sixty-Third World Health Assembly, World Health Organization. WHO Guiding Principles on Human Cell, Tissue and Organ Transplantation. Cell Tissue Bank 2010;11:413-9.

57. Marchac A, Kuschner T, Paris J, Picard A, Vazquez MP, et al. Ethical issues in pediatric face transplantation: should we perform face transplantation in children? Plast Reconstr Surg 2016;138:449-54.

58. Amaral S, Levin LS. Pediatric and congenital hand transplantation. Curr Opin Organ Transplant 2017;22:477-83.

59. Leijte JA, Kirrander P, Antonini N, Windahl T, Horenblas S. Recurrence patterns of squamous cell carcinoma of the penis: recommendations for follow-up based on a two-centre analysis of 700 patients. Eur Urol 2008;54:161-8.

60. Pomahac B, Alhefzi M, Bueno EM, McDiarmid SV, Levin LS. Living donation of vascularized composite allografts. Plast Reconstr Surg 2018;142:405e-11.

61. Sopko NA, Tuffaha SH, Lough D, Brandacher G, Lee WPA, et al. Penile allotransplantation for complex genitourinary reconstruction. J Urol 2017;198:274-80. 